\title{
Simplified Control Method for Unified Power Quality Conditioner (UPQC)
}

\author{
Metin Kesler ${ }^{1}$, Engin Ozdemir ${ }^{2}$ \\ ${ }^{1,2}$ Technical Education Faculty \\ Kocaeli University, 41380 Umuttepe Kocaeli Turkey \\ Phone number: +90 2623032248 e-mail: ${ }^{1}$ metinkesler@kocaeli.edu.tr, ${ }^{2}$ eozdemir@kocaeli.edu.tr
}

\begin{abstract}
Unified Power Quality Conditioner (UPQC) for harmonic elimination and simultaneous compensation of voltage and current, which improves the power quality offered for other harmonic sensitive loads. UPQC consist of combined series active power filter that compensates voltage harmonics of the power supply, and shunt active power filter that compensates harmonic currents of a non-linear load. In this paper a new control algorithm for the UPQC system is optimized and simplified without transformer voltage, load and filter current measurement, so that system performance is improved. The proposed control technique has been evaluated and tested under dynamical and steady state load conditions using PSIM software. The laboratory prototype experimental results for shunt active filter part are given.
\end{abstract}

\section{Key words}

Unified Power Quality Conditioner (UPQC), harmonics, active power filter, power quality.

\section{Introduction}

Unified power quality control was widely studied by many researchers as an eventual method to improve power quality of electrical distribution system [1-3]. The function of unified power quality conditioner is to eliminate the disturbances that affect the performance of the critical load in power system. In other words, the UPQC has the capability of improving power quality at the point of installation on power distribution systems. The UPQC, therefore, is expected to be one of the most powerful solutions to large capacity loads sensitive to supply voltage flicker/imbalance [2]. The UPQC, which has two inverters that share one dc link, can compensate the voltage sag and swell, the harmonic current and voltage, and control the power flow and voltage stability. Besides, the UPQC can also compensate the voltage interruption if it has some energy storage or battery in the dc link [3].

Turkish Energy Market Regulatory Authority (EPDK) announced a new regulation, number 25639 and date 10.11.2004 namely "Electricity Transmission System
Supply Reliability and Quality Regulation" and the power factor was increased stepwise. The reactive energy transmission in Turkish electrical distribution system is arranged in this regulation given in Table I. In Table I, reactive energy limits are 0.98 in inductive and 0.988 in capacitive region [4].

Table I. Active and reactive energy consumption ranges.

\begin{tabular}{|l|c|c|c|}
\hline \multirow{2}{*}{ Limits } & \multicolumn{3}{|c|}{ Energy Consumption /Month } \\
\cline { 2 - 4 } & $\begin{array}{l}\text { Active } \\
\text { (\%) }\end{array}$ & Inductive & Capacitive \\
\hline $\begin{array}{l}\text { Loads in } \\
\text { distribution } \\
\text { system has power } \\
\text { lower than 50 } \\
\text { kVA }\end{array}$ & 100 & $\leq 33$ & $\leq 20$ \\
\hline $\begin{array}{l}\text { Loads in } \\
\text { distribution } \\
\text { system has power } \\
\text { higher than 50 } \\
\text { kVA }\end{array}$ & 100 & $\leq 20$ & $\leq 15$ \\
\hline
\end{tabular}

The new reactive energy rates cause installation of new shunt capacitive banks in Turkish electrical distribution system. The compensation power is increased and caused parallel resonance event risk at the utility-consumer point of common coupling (PCC). However, in consequence of over compensation, generated harmonics are increased. Higher harmonic rates cause new problems in facilities.

In this paper, the proposed control algorithm for the UPQC is optimized and simplified without transformer voltage, load and filter current measurement, so that system performance is improved. The proposed control technique has been evaluated and dynamically tested under different load conditions using PSIM software. 


\section{Unified Power Quality Conditioner}

Fig. 1 shows a basic system configuration of a general UPQC consisting of the combination of a series active power filter and shunt active power filter. The main aim of the series active power filter is harmonic isolation between a sub-transmission system and a distribution system; it has the capability of voltage flicker/ imbalance compensation as well as voltage regulation and harmonic compensation at the utility-consumer point of common coupling (PCC). The shunt active power filter is used to absorb current harmonics, compensate for reactive power and negative-sequence current, and regulate the dc-link voltage between both active power filters.

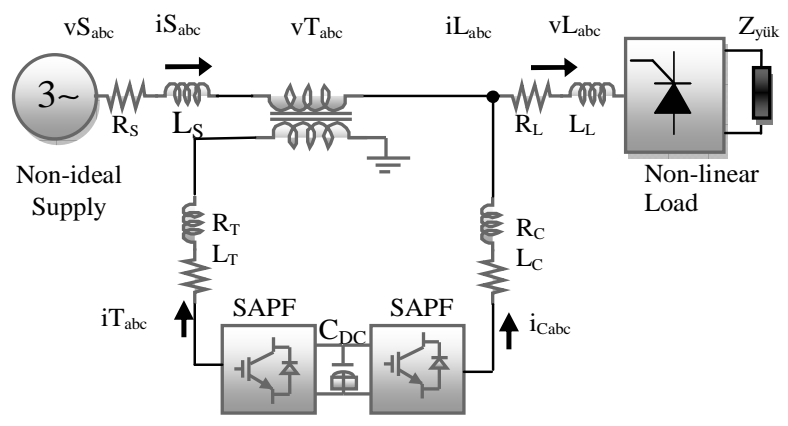

Fig. 1. Unified Power Quality Conditioner configuration.

\section{The Proposed UPQC Control Algorithm}

The proposed UPQC control algorithm block diagram in PSIM simulation software is shown in Fig. 2.

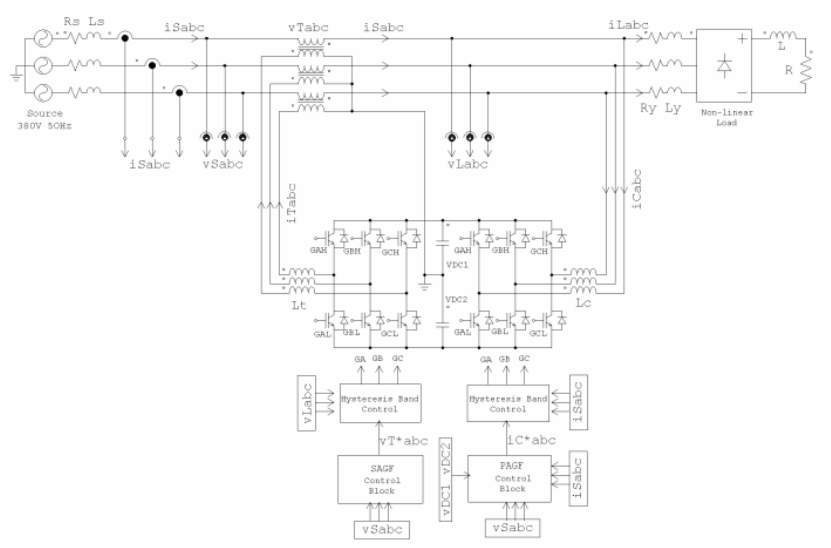

Fig. 2. The proposed UPQC control algorithm block diagram.

\section{A. Series active power filter control algorithm}

The proposed series active power filter control algorithm is shown in Fig. 3. In equation (1), supply voltages $v_{S a b c}$ are transformed abc to dq0. In addition, PLL conversion is used for reference voltage calculation.

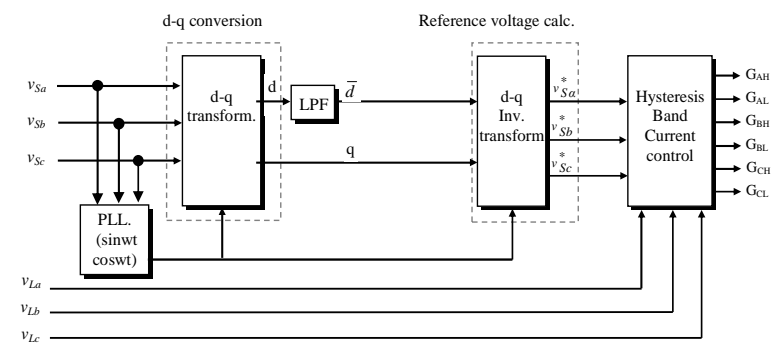

Fig. 3. Series active power filter control block diagram.

$\left[\begin{array}{c}\mathrm{v}_{0} \\ \mathrm{v}_{\mathrm{d}} \\ \mathrm{v}_{\mathrm{q}}\end{array}\right]=\frac{2}{3}\left[\begin{array}{ccc}\frac{1}{2} & \frac{1}{2} & \frac{1}{2} \\ \sin (\mathrm{wt}) & \sin \left(\mathrm{wt}-2 \frac{\pi}{3}\right) & \sin \left(\mathrm{wt}+2 \frac{\pi}{3}\right) \\ \cos (\mathrm{wt}) & \cos \left(\mathrm{wt}-2 \frac{\pi}{3}\right) & \cos \left(\mathrm{wt}+2 \frac{\pi}{3}\right)\end{array}\right]\left[\begin{array}{c}v_{S a} \\ v_{S b} \\ v_{S c}\end{array}\right]$

Voltage in $\mathrm{d}$ axes $\left(\mathrm{v}_{\mathrm{d}}\right)$ given in equation (2) is composed from DC and AC components $\left(\overline{\mathrm{v}}_{\mathrm{d}}\right.$ and $\left.\widetilde{\mathrm{v}}_{\mathrm{d}}\right) . \overline{\mathrm{v}}_{\mathrm{d}}$ Voltage is calculated by using LPF (low pass filter).

$\mathrm{v}_{\mathrm{d}}=\overline{\mathrm{v}}_{\mathrm{d}}+\tilde{\mathrm{v}}_{\mathrm{d}}$

$v_{S a b c}^{*}$ reference voltages are calculated as given in equation (3). The switching signals are assessed reference voltages $\left(v_{S a b c}^{*}\right)$ load voltages $\left(v_{L a b c}\right)$ and via hysteresis band current control.

$\left[\begin{array}{c}v_{S \alpha}^{*} \\ v_{S b}^{*} \\ v_{S c}^{*}\end{array}\right]=\frac{2}{3}\left[\begin{array}{ccc}\sin (\mathrm{wt}) & \cos (\mathrm{wt}) & 1 \\ \sin \left(\mathrm{wt}-2 \frac{\pi}{3}\right) & \cos \left(\mathrm{wt}+2 \frac{\pi}{3}\right) & 1 \\ \sin \left(\mathrm{wt}+2 \frac{\pi}{3}\right) & \cos \left(\mathrm{wt}+2 \frac{\pi}{3}\right) & 1\end{array}\right]\left[\begin{array}{c}\overline{\mathrm{v}}_{\mathrm{d}} \\ \mathrm{v}_{\mathrm{q}} \\ \mathrm{v}_{0}\end{array}\right]$

\section{B. Shunt active power filter control algorithm}

The proposed shunt active power filter control algorithm is shown in Fig. 4. Instantaneous reactive power ( $p-q)$ theory is used to control of shunt active power filter in real time. In this theory, instantaneous three-phase current and voltages are transformed to $\alpha-\beta-0$ from a-b-c coordinates as shown in equation (4) and (5).

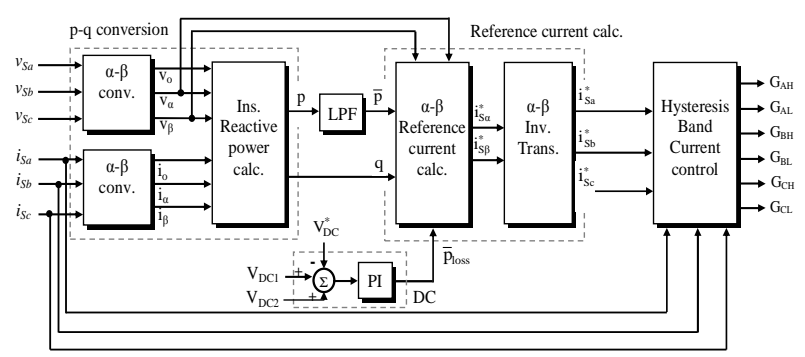

Fig. 4. Shunt active power filter control block diagram. 
$\left[\begin{array}{c}\mathrm{v}_{0} \\ \mathrm{v}_{\alpha} \\ \mathrm{v}_{\beta}\end{array}\right]=\sqrt{\frac{2}{3}}\left[\begin{array}{ccc}1 / \sqrt{2} & 1 / \sqrt{2} & 1 / \sqrt{2} \\ 1 & -1 / 2 & -1 / 2 \\ 0 & \sqrt{3} / 2 & -\sqrt{3} / 2\end{array}\right]\left[\begin{array}{c}\mathrm{v}_{\mathrm{Sa}} \\ \mathrm{v}_{\mathrm{Sb}} \\ \mathrm{v}_{\mathrm{Sc}}\end{array}\right]$

$\left[\begin{array}{c}\mathrm{i}_{0} \\ \mathrm{i}_{\alpha} \\ \mathrm{i}_{\beta}\end{array}\right]=\sqrt{\frac{2}{3}}\left[\begin{array}{ccc}1 / \sqrt{2} & 1 / \sqrt{2} & 1 / \sqrt{2} \\ 1 & -1 / 2 & -1 / 2 \\ 0 & \sqrt{3} / 2 & -\sqrt{3} / 2\end{array}\right]\left[\begin{array}{c}\mathrm{i}_{\mathrm{Sa}} \\ \mathrm{i}_{\mathrm{Sb}} \\ \mathrm{i}_{\mathrm{Sc}}\end{array}\right]$

Load side instantaneous real and imaginary power components are calculated by using load currents and phase-neutral voltages as given in equation (6).

$\left[\begin{array}{l}\mathrm{p} \\ \mathrm{q}\end{array}\right]=\left[\begin{array}{cc}\mathrm{v} & \mathrm{v} \\ \alpha & \beta \\ -\mathrm{v}_{\beta} & \mathrm{v} \\ & \alpha\end{array}\right]\left[\begin{array}{c}\mathrm{i} \\ \alpha \\ \mathrm{i} \\ \beta\end{array}\right]$

Instantaneous real and imaginary powers include $\mathrm{AC}$ and DC components as shown in (7). DC components of $p$ and $q$ composed from positive sequence components $(\overline{\mathrm{p}}$ and $\bar{q}$ ) of load current. AC components ( $\tilde{p}$ and $\tilde{q}$ ) of $p$ and $\mathrm{q}$ include harmonic and and negative sequence components of load currents [5].

In order to reduce neutral current, $\mathrm{p}_{0}$ was calculated by using DC and AC components of imaginary power and $\mathrm{AC}$ component of real power; as given in (8) if both harmonic and reactive power compensation is required

$p_{0}=v_{0} * i_{0} \quad ; \quad \mathrm{p}=\overline{\mathrm{p}}+\tilde{\mathrm{p}}$

$\left[\begin{array}{c}i_{S \alpha}^{*} \\ i_{S \beta}^{*}\end{array}\right]=\frac{1}{v_{\alpha}^{2}+v_{\beta}^{2}}\left[\begin{array}{cc}v_{\alpha} & -v_{\beta} \\ v_{\beta} & v_{\alpha}\end{array}\right]\left[\begin{array}{c}-\tilde{p}+p_{0}+\bar{p}_{\text {loss }} \\ -q\end{array}\right]$

$\mathrm{i}_{\mathrm{s} \alpha}{ }^{*}$ and $\mathrm{i}_{\mathrm{s} \beta}{ }^{*}$ are reference currents of shunt active power filter in $\alpha-\beta$ coordinates. These currents are transformed to three-phase system as shown below in equation (9).

$\left[\begin{array}{c}i_{S a}^{*} \\ i_{S b}^{*} \\ i_{S c}^{*}\end{array}\right]=\sqrt{\frac{2}{3}}\left[\begin{array}{cc}1 & 0 \\ -1 / 2 & \sqrt{3 / 2} \\ -1 / 2 & -\sqrt{3 / 2}\end{array}\right]\left[\begin{array}{c}i_{S \alpha}^{*} \\ i_{S \beta}^{*}\end{array}\right]$

The reference currents in three-phase system $\left(i{ }^{*}{ }_{s a} i^{*}{ }_{s b}\right.$ ve $\mathrm{i}_{\mathrm{sb}}$ ) are calculated in order to compensate neutral, harmonic and reactive currents in the load. The switching signals used in shunt active power filter control algorithm are generated by comparing reference currents and actual line currents and using hysteresis band current control algorithm [6].

\section{Simulation Results}

In this study, a new simplified control algorithm for UPQC is evaluated by using simulation results given in PSIM software. The proposed and simulated UPQC system parameters are given in Table II. In simulation studies, the result are specified before and after UPQC system is operated. In addition, when UPQC system is operated, load has changed and dynamic response of the system was tested. The proposed control algorithm has considerably good simulation results as compared the conventional control algorithms.

Table II. UPQC simulation parameters.

\begin{tabular}{l|l|l}
\hline \multicolumn{3}{c}{ System parameters } \\
\hline Supply voltages & $\mathrm{v}_{\text {Sabc }}$ & $380 \mathrm{~V}$ \\
\hline Supply frequency & $\mathrm{f}_{\mathrm{S}}$ & $50 \mathrm{~Hz}$ \\
\hline DC link voltage & $\mathrm{V}_{\mathrm{DA}}$ & $750 \mathrm{~V}$ \\
\hline
\end{tabular}

Series active power filter parameters

\begin{tabular}{l|l|l}
\hline Series transformer & Rate & $1 / 3$ \\
\hline AC filter & $\mathrm{R}_{\mathrm{f}} \mathrm{C}_{\mathrm{f}}$ & $5 \Omega, 3 \mu \mathrm{F}$ \\
\hline AC inductance & $\mathrm{L}_{\mathrm{C}}$ & $3.5 \mathrm{mH}$ \\
\hline Switching frequency & $\mathrm{f}_{\mathrm{S}}$ & $10 \mathrm{kHz}$ \\
\hline
\end{tabular}

Shunt active power filter parameters

\begin{tabular}{l|l|l}
\hline AC inductance & $\mathrm{L}_{\mathrm{LA}}$ & $1 \mathrm{mH}$ \\
\hline DC resistance & $\mathrm{R}_{\mathrm{LD}}$ & $100 \Omega$, \\
\hline DC inductance & $\mathrm{L}_{\mathrm{LD}}$ & $10 \mathrm{mH}$ \\
\hline DC capacitor & $\mathrm{C}_{\mathrm{DC}}$ & $2200 \mu \mathrm{F}$ \\
\hline
\end{tabular}

\begin{tabular}{l|l|l}
\hline \multicolumn{3}{c}{ Total Harmonic Distortion \% (THD) } \\
\hline & Before Filter & After Filter \\
\hline$v_{\text {Sabc }}$ & 16 & 16 \\
\hline$v_{\text {Labc }}$ & 16 & 3.1 \\
\hline$i_{\text {Sabc }}$ & 29.3 & 4.2 \\
\hline$i_{\text {Labc }}$ & 29.3 & 29.3 \\
\hline
\end{tabular}

In the proposed control algorithm, load currents ( $\left.i_{\text {Labc }}\right)$, mains currents $\left(i_{\text {Sabc }}\right)$, mains voltages $\left(v_{\text {Sabc }}\right)$ and load voltages $\left(\mathrm{v}_{\text {Labc }}\right)$ waveforms are shown in Fig. 5, before and after UPQC system is operated. The neutral current compensation results are given in Fig. 6. Load-mains current and voltage waveforms in phase "a" are shown in Fig. 7. The proposed UPQC control algorithm has ability to compensate both harmonics and reactive power of the load and neutral current is also eliminated.

Finally, the voltage and current harmonic compensation capability of the proposed UPQC control technique is shown in Table II as THD levels. The obtained results show that the proposed control technique allows the \%3.1 mitigation of all harmonic components. 


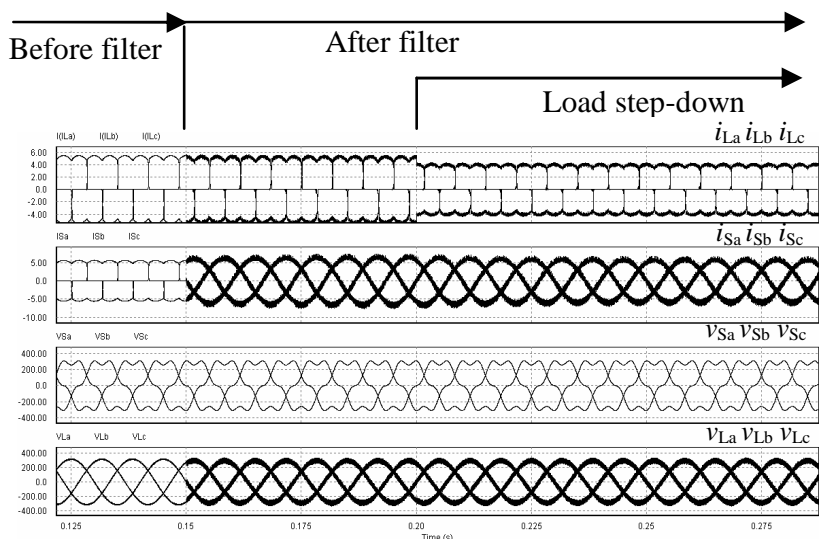

Fig. 5. Mains-load current and voltage waveforms when UPQC system is operated.

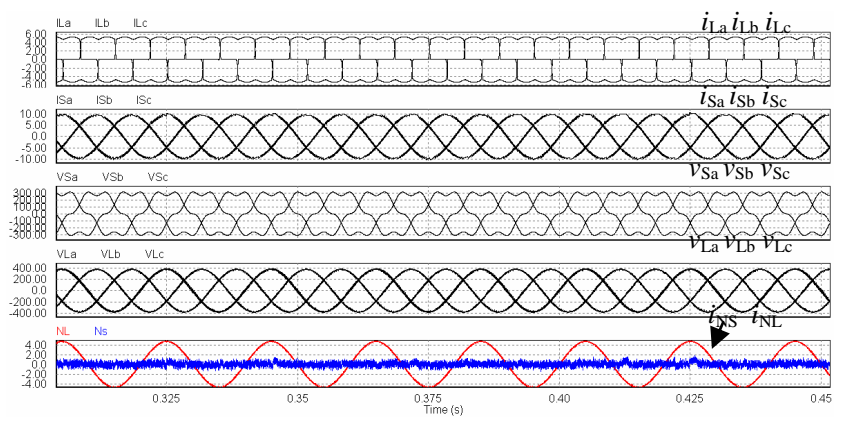

Fig. 6. Load-mains currents and voltage waveforms.

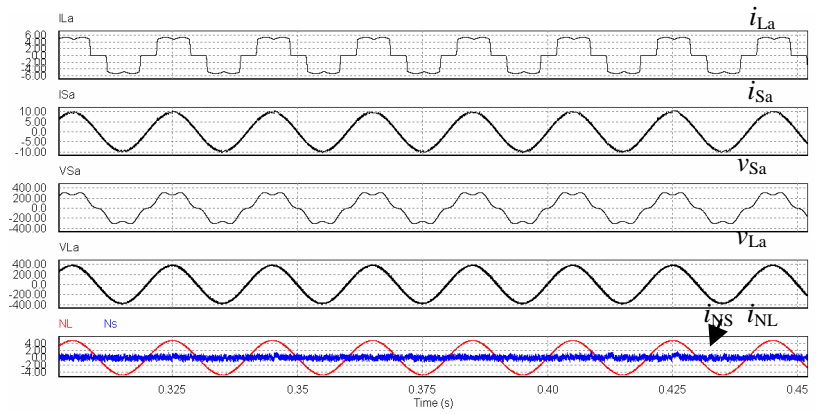

Fig. 7. Load-mains current and voltage waveforms in phase "a".

\section{Experimental results}

The feasibility of hardware implementation for the proposed control algorithm was evaluated by design and experimentation of three-phase three-wire UPQC. A three-phase diode-bridge rectifier with the R-L load as the nonlinear load is connected to $\mathrm{AC}$ mains to demonstrate the effectiveness of the UPQC with the proposed method.

The aim of the UPQC system is not only to compensate for the current harmonics produced by a diode-bridge rectifier of $10 \mathrm{kVA}$, but also to eliminate the voltage harmonics contained in the receiving terminal voltage from the load terminal voltage. The UPQC consists of a 1.5 -kVA series-active filter and a $2.5-\mathrm{kVA}$ shunt-active filter. The dc links of both active filters are connected to a common dc capacitor of 1100 microfarad and $700 \mathrm{~V}$
DC. The diode-bridge rectifier is considered a harmonic producing load identical to a de power supply that can found in any power electronics based system.

The proposed control technique is implemented on the TMS320F28335 DSP board. F28335 DSP has an internal $68 \mathrm{kB}$ RAM, 2 kB OTP ROM, $512 \mathrm{kB}$ flash, 18 channels pulse width modulation (PWM), 12-bit 16 channels analog-to-digital (A/D) converters, expansion interfaces and parallel port JTAG interface. It can perform parallel multiply and arithmetic logic unit (ALU) on integer or floating point data in a $6.67 \mathrm{~ns}$ single cycle instruction time with a peak computation rate of 150 million instruction per second (MIPS).

The source voltage and current signals are measured LEM hall-effect sensor. Semikron SEMIX 101GD128Ds IGBT modules and the CONCEPT 6SD106EI six-pack IGBT driver modules are used for driving the IGBT switches in power part of the UPQC system. IGBT driver module has short circuit and over current protection functions for every IGBT and provides electrical isolation of all PWM signals applied to DSP.

Fig. 8 shows source voltage and current waveform before filtering. After compensation, source current becomes sinusoidal and in phase with the source voltage; hence, both harmonics and reactive power are compensated simultaneously. Before harmonic compensation the THD of the supply current was $29.13 \%$ and after the harmonic compensation, it was reduced to $5.75 \%$ which complies with the IEEE 519 harmonic standards.

The source current and filter current experimental results for proposed control of shunt active power filter part of UPQC system are shown in Fig. 9-11 before and after filter operated. Fig.12 shows experimental results for source current $\left(\mathrm{i}_{\mathrm{Sa}}\right)$ harmonic spectrum before filter and after filter. These experimental results given above shows that the power quality compensation features of UPQC, by appropriate control of shunt APF can be done effectively.

The experimental laboratory prototype series active power filter part is installing and experimental results are planning to publish in future papers.

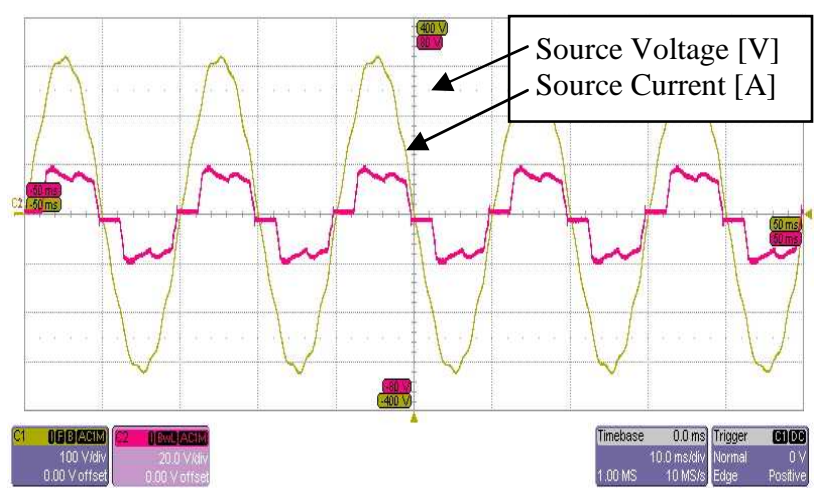

Fig. 8. Experimental results for source voltage $\left(\mathrm{v}_{\mathrm{Sa}}\right)$ and source current $\left(\mathrm{i}_{\mathrm{Sa}}\right)$ before filter operation. 


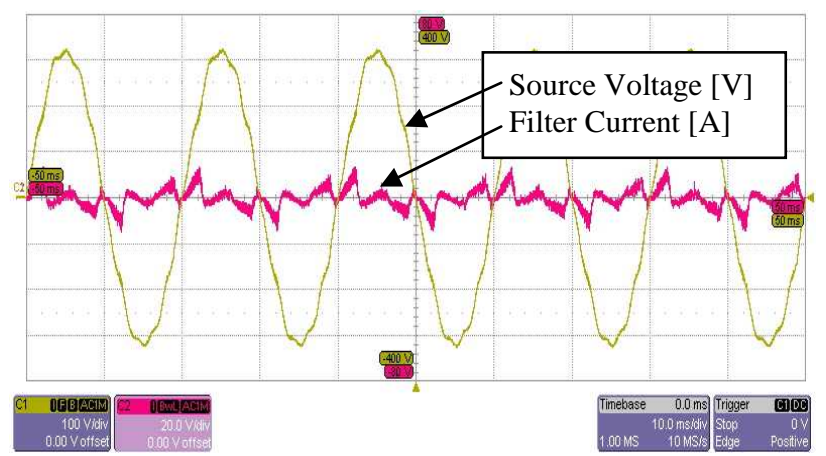

Fig. 9. Experimental results for source voltage $\left(\mathrm{v}_{\mathrm{Sa}}\right)$ and filter current $\left(\mathrm{i}_{\mathrm{Ca}}\right)$ after filter operation.

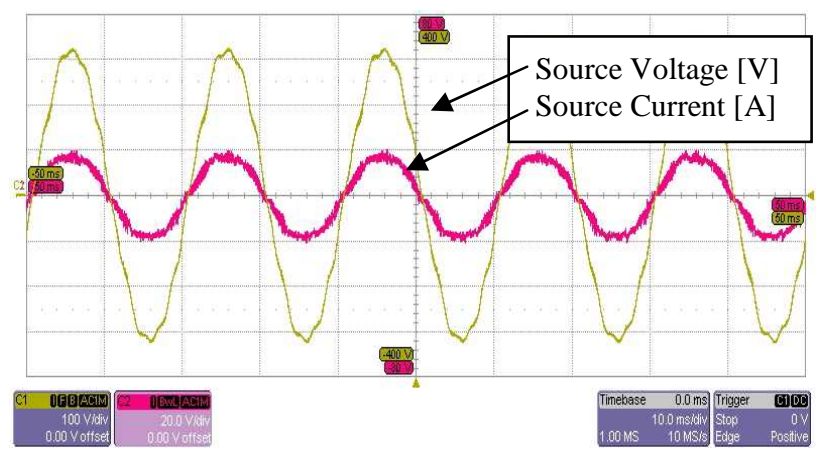

Fig. 10. Experimental results for source voltage $\left(\mathrm{v}_{\mathrm{Sa}}\right)$ and source current $\left(\mathrm{i}_{\mathrm{Sa}}\right)$ after filter operation.

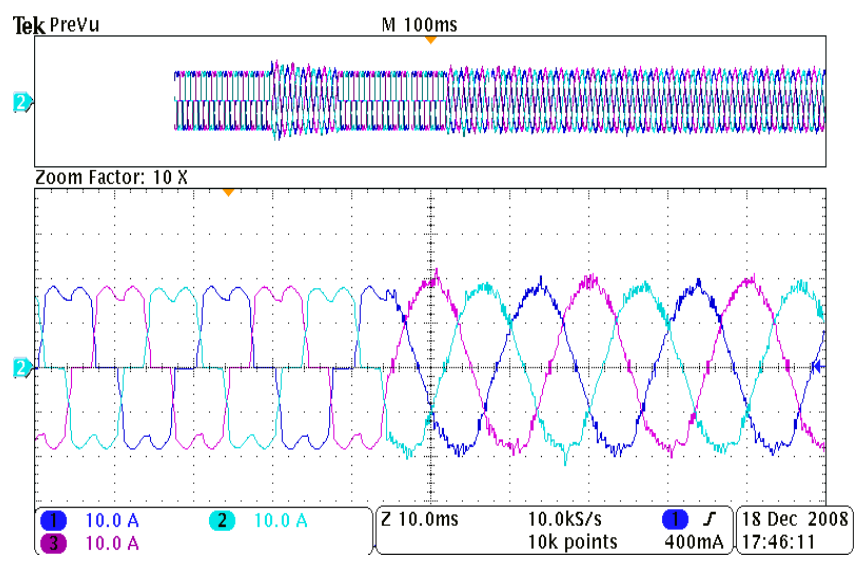

Fig. 11. Experimental results for source currents $\left(i_{\text {Sabc }}\right)$ before and after filter operation.

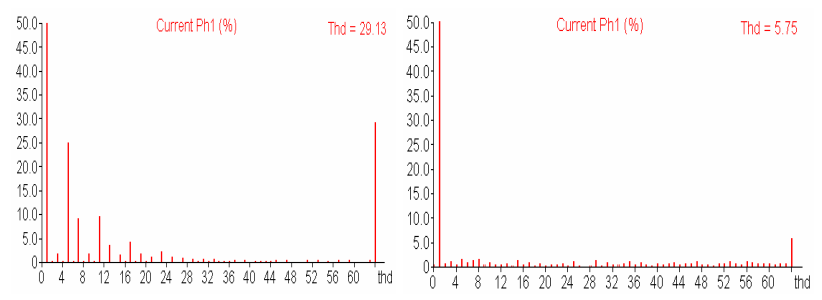

Fig. 12. Experimental results for source current $\left(\mathrm{i}_{\mathrm{Sa}}\right)$ harmonic spectrum before and after filter operation.

\section{Conclusion}

In this study, a new simplified control algorithm is proposed for UPQC system in order to compensate power quality problems such as, unbalanced voltages, harmonics, reactive power and neutral current of the nonlinear loads. The proposed control algorithm simulation results are given in PSIM simulation. In literature, conventional UPQC control algorithms require measurements of load, filter and mains currents and voltages and also DC bus voltage in order to regulate DC bus. The proposed control algorithm, the number of measurement is decreased. In this study successful simulation results are given in PSIM simulation software. The laboratory prototype experimental results for shunt active filter part are given.

\section{Acknowledgement}

This study is supported financially by TUBITAK research fund number 108E083 and Kocaeli University Scientific Research Fund. This work is also supported by Concept Inc. (Concept IGBT Driver), Semikron Inc. (IGBT and IGBT Driver), LEM Inc. (Voltage and Current sensor) and TI Inc. (F28335 eZdsp), which is gratefully acknowledged. The authors gratefully acknowledge the contributions of Halim Özmen (from Semikron Turkey) and Robert Owen (from TI).

\section{References}

[1] Akagi, H. and Fujita, H., "A new power line conditional for harmonic compensation in power systems," IEEE Trans. Power Del., vol. 10, no. 3, pp. 1570-1575, Jul. 1995.

[2] Fujita, H. and Akagi, H., "The unified power quality conditioner: The integration of series and shunt-active filters," IEEE Trans. Power Electron., vol. 13, no. 2, pp. 315-322, Mar. 1998.

[3] H. Akagi, E. H. Watanabe and M. Aredes, Instantaneous Power Theory and Applications to Power Conditioning. Wiley-IEEE Press. April 2007.

[4] Turkish Energy Market Regulatory Authorithy (EPDK) regulation, number 25639 and date 10.11.2004 "Electricity Transmission System Supply Reliablity and Quality Regulation”.

[5] Dusan Graovac, Vladimir A. Katic and Alfred Rufer, "Power Quality Problems Compensation with Universal Power Quality Conditioning System", IEEE Transaction on Power Delivery, VOL. 22, NO. 2, (2007).

[6] B. Han, Senior Member, IEEE, B. Bae, H. Kim, and S. Baek, "Combined Operation of Unified Power-Quality Conditioner With Distributed Generation," IEEE Transaction on Power Delivery, VOL. 21, No. 1, (2006).

[7] Kesler M., "Design and DSP based control of a Shunt Active Power Filter" Kocaeli University, M.Sc. Thesis, (July, 2005). 